\title{
Filtering Out Standard Success Criteria in the Case of Multi-Mode Standardization: Responsible Waste Water Treatment
}

\author{
Geerten van de Kaa ${ }^{1, *}$, Lieke van den Eijnden ${ }^{2}$ and Neelke Doorn ${ }^{1}$ (i) \\ 1 Faculty of Technology, Policy, and Management, Delft University of Technology, 2628 BX Delft, \\ The Netherlands; N.Doorn@tudelft.nl \\ 2 Fluor corporation, 2132 LS Hoofddorp, The Netherlands; liekevandeneijnden@gmail.com \\ * Correspondence: g.vandekaa@tudelft.nl
}

Received: 16 January 2020; Accepted: 19 February 2020; Published: 22 February 2020

\begin{abstract}
Standardization can be achieved in multiple ways; firms may join forces and develop standards in standardization committees, they may compete directly on the market in standards battles, or governmental agencies may impose standards. This paper studies criteria for the selection of standards in a situation in which these three forms of standardization occur simultaneously (multi-mode standardization). The paper attempts to arrive at weights for these criteria by applying them to the case of phosphorus recovery from municipal waste water, a technological process that fits the transition to a circular economy but that is still lacking standardization. A contribution is made to the standardization literature by empirically studying the case of multi-mode standardization and by applying standard success criteria to the area of water treatment.
\end{abstract}

Keywords: standardization; standards; Best-Worst Method; BWM; waste water treatment

\section{Introduction}

When sewage water drains into major drainage basins without treatment, this may have serious negative impacts on both the environment and on physical well-being. Moreover, with the discharge of waste water, some valuable nutrients also get lost, such as phosphorus or nitrogen. A responsible and sustainable way of dealing with this waste water is by treating it, while at the same time, extracting the nutrients from the waste water for future re-use.

In this process, phosphorus is removed and recovered from municipal waste water at various stages in a municipal waste water treatment plant. It is captured from the sludge of the treatment plant in two standard ways: through chemical treatment or through biological treatment. Facilities prefer to apply a purely biological treatment for reasons of sustainability; that is, it is better for the environment as no chemicals are added to the water. The phosphate that is captured is an essential and non-renewable resource for the growth of a living organism and recovering the phosphate allows for re-use. It thereby fits in the transition to a circular approach in the water sector. This provides the motivation for facilities to strive for biological treatment and phosphate recovery. However, sometimes, a combination of biological and chemical treatment may be needed when the effluent concentrations of the water cannot be reached by the former only [1].

In the Netherlands, over the years, phosphorus is removed in more and more treatments plants, and the method of biological treatment is gaining popularity over chemical treatment (see Figure 1). In 2016, 299 of the 327 treatment plants in the Netherlands had a system for the recovery removal of phosphorus. Of these 299 plants, 46 treatments plants applied chemical treatment, and 120 treatment plants applied biological treatment, while 133 treatment plants applied a combination of both treatments. 
This paper focuses on the case of phosphorous recovery through so-called struvite formation from municipal waste water [1-3].

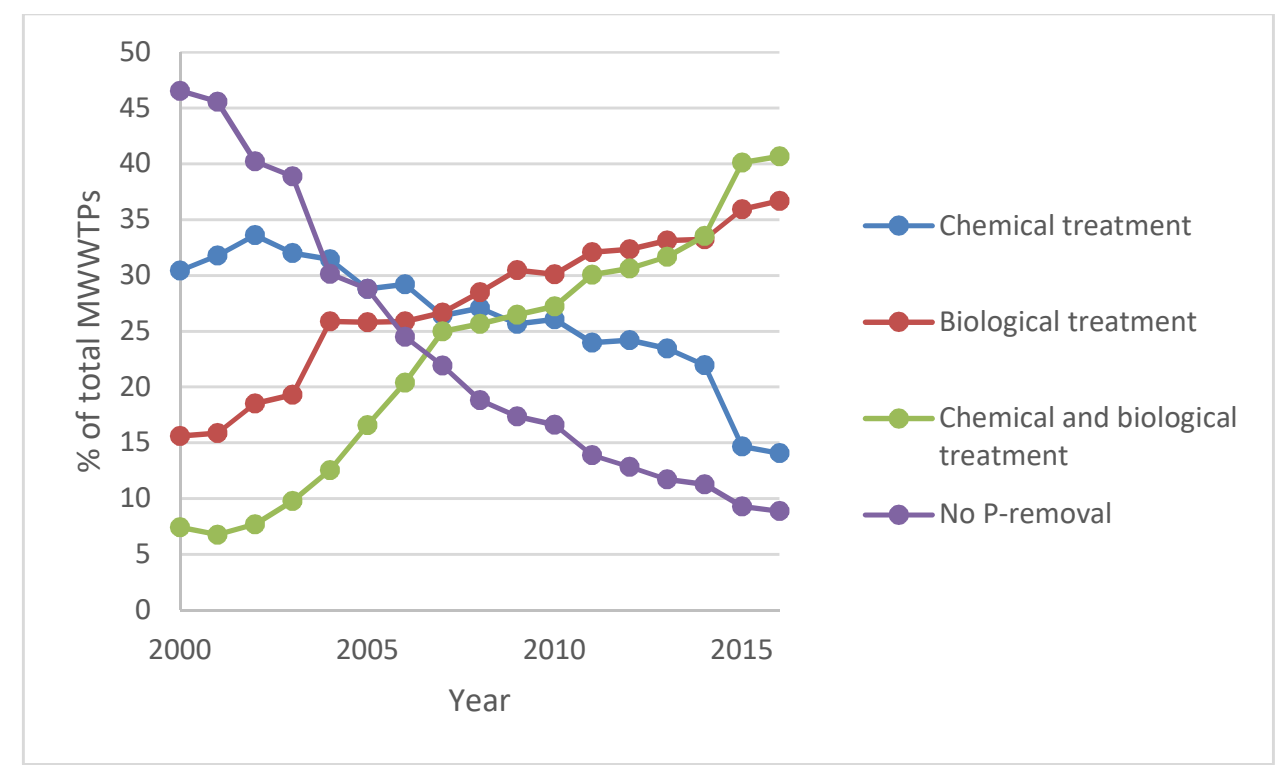

Figure 1. Implementation of standards for phosphorus removal in the Netherlands [4].

The recovery of phosphorus described above can be seen as a situation that typically fits the ideal of Responsible Research and Innovation (RRI): not focusing on one function or goal of the treatment plant at the expense of other functions but trying to address multiple goals with one approach [5]. However, although the potential is there, a challenge here is that stakeholders do not yet agree upon which method is best equipped for phosphorus recovery and that coordination on how to get such agreement is also lacking.

The topic of how coordination can be achieved in large socio-technological systems is a topic that has been studied by many scholars. In these systems, coordination should be established between system components, actors, and the values they deem important. One way to achieve coordination is through standardization. Indeed, in the development of technological products and innovation, standardization is the dominant form to achieve compatibility among products. Although the importance of standardization is evident, it is an under-investigated phenomenon [6]. In that respect, the scarce literature that does investigate the phenomenon distinguishes between three forms of standardization: market-based, committee-based, and government-based standardization [7]. In market-based standardization, actors arrive at coordination through competition. Examples of cases of market-based standardization that have been reported in the literature include the standards battle for a video recorder format (Betamax vs VHS) [8] and the various standards battles that occurred for video game console platforms (e.g., Xbox vs PlayStation 2) [9]. In committee-based standardization, coordination occurs through cooperation by stakeholders. This cooperation may take place in committees of standard developing organizations (SDOs), such as the international telecommunications institute (ITU) or consortia (such as the Blu-ray disc association). Government-based standardization refers to a situation whereby governmental agencies impose standards, and, whereby, coordination is thus achieved through hierarchy.

Recently, the thought has been put forward that these different forms of standardization may occur simultaneously in a form of 'multi-mode standardization' [7]. This is essentially a combination of the three forms of standardization. This may, for example, occur when formal standards are developed in committees and a firm that is not involved in that committee develops and promotes a competing standard. This occurred in the battle between Firewire and USB [10], where competing standards were developed in a committee and in a consortium. In addition, firms may compete with each 
other in formal standards committees as was the case for the WIFI standard [11]. In these situations, committee-based and market-based standardization occurs simultaneously. If a government would also intervene in these standardization processes and impose a third standard, a 'complete' form of multi-mode standardization would occur, including all three forms of standardization in parallel. Recent cases where all three modes occurred in parallel are the case of the electric vehicle recharging plugs in Europe. Two different plugs (i.e., the Mennekes plug and the Scame plug) were introduced by different parties based on the requirements set by the International Electrotechnical Commission. These two plugs were available on the market and were dependent on the car brand. In the end, the European Commission decided that the Mennekes plug would become the European standard [12]. Indeed, in many cases of standards battles the competitors consist of large consortia in which multiple firms cooperate. In this situation, market-based standardization and committee-based standardization occur in parallel.

The question that is studied in this paper is which factors affect the selection of standards in situations of multi-mode standardization and their relative importance according to experts. The paper aims to answer that question by conducting a literature study into factors for multi-mode standard selection. It applies the factors to the case of standardization for phosphorous recovery through struvite formation from municipal waste water.

The paper contributes to the literature on standardization by providing a more comprehensive overview of factors for standard selection taking into account various forms of standardization. Furthermore, we assign weights to factors for standard selection for the case of phosphorus recovery through struvite formation. Although prior research has focused on standards for non-sewered sanitation systems [13], this is one of the first studies that investigates standardization in the area of water treatment.

The paper starts with a literature review in order to arrive at factors for standard success within the three forms of standardization. These factors will be studied in the context of multi-mode standardization. In Section 3, the method that is applied in the paper is described. Then, the results are presented, analyzed, and discussed.

\section{Theory}

Various authors have studied factors for standard selection in a market-based and committee-based standardization context [11,14-28]. They report on factors that affect the chances that a standard committee or consortium reaches consensus about the contents of a standard (committee-based standardization) and factors that affect the chances that a standard reaches market dominance (market-based standardization). These factors relate to various aspects of the standard, the standard supporter, its standard support strategies, other stakeholders, and market mechanisms.

One of the most important factors affecting standard success is the 'current installed base' [29] which refers to the number of products that have been sold with the implemented standard. This factor is important as standards-based markets are characterized by increasing returns to adoption resulting from the existence of network externalities; that is, products increase in value the more they are being used by consumers. As installed base is so important for establishing standard success in a market, various scholars have attempted to explain how the installed base can be increased.

First, a greater overall strength of the group of standard supporters has an effect on the outcome of the standardization process. Strength is, in part, determined by financial resources (financial strength) that are required to pay for the costs to participate in standardization and which affect the negotiation power of a firm. For firms, financial resources are also needed to effectively apply strategies, including marketing. Another aspect is the brand reputation and credibility that was created in earlier standardization processes, which can help with creating legitimacy $[30,31]$. Furthermore, when a firm has superior complementary assets, this can help to gain an advantage in the standardization process [27]. The 'learning orientation' refers to the ability to learn from previous experiences or from each other in inter-firm collaborative arrangements. 
Several aspects of the composition of a standardization committee have been shown to play a role in influencing the outcome of standardization in committees and in the market. The composition of the committee (in terms of its size and diversity) may positively influence market dominance of the standard. For example, related to size, firms can send a lot of their employees to committee meetings in order to gain enough voting points [11]. However, increased committee size may also negatively affect the chances that an agreement is reached within a committee [14,23]. The size of a committee can be influenced via increasing the exclusivity of a committee (e.g., by letting participants pay participation fees). Consensus can be reached in multiple ways and the specific 'voting rules' that are chosen within the committee affect whether consensus is likely to be reached. Firms may try to acquire a central position in the committee, such as that of committee leader, but the position that a firm can take in a committee is determined by the point in time that the firm starts with participating in a committee.

Technical characteristics of the standard may have an effect on it becoming selected. 'Technological superiority' is one aspect and refers to all aspects of the standard that make it better compared to other standards. It can be increased by adapting the standard to changing user requirements [30]. Another aspect relating to technological characteristics is 'compatibility' with e.g., a previous generation (backwards compatibility). Finally, the availability of complementary goods positively affect the chances that the standard is chosen by consumers. This is especially the case for standards that apply to platforms (such as video gaming consoles and video/DVD players).

Standard support strategies are also mentioned in the literature. This refers to, for example, 'pricing strategy'. To create market share, firms sometimes make use of penetration pricing in products in which the standards are implemented. In addition, firms may make use of an 'appropriability strategy' whereby standards are made available for free (e.g., unpatented). This may create an installed base quickly, as was the case for Sun's Java [32]. Another strategy concerns 'marketing communications'. Through, for example, pre-announcements, anticipated installed base can be positively increased, and, as expectations count for a lot in standards based markets, this will further increase installed base.

Moreover, different stakeholders (such as governmental agencies) can offer financial support to help implement a standard. Timing of entry in the market of a standard is also relevant. Early entry may positively relate to success of a standard. A government can enforce a standard on the market and, as it potentially has a strong purchasing power, it can act as a large buyer of products in which the standards are applied. That positively affects market dominance of the standard. Finally, commitment is an important factor that may positively affect standard success. When firms are not committed to the standardization process, they may be less successful than firms that are committed. In committees, stakeholders can use a form of 'agenda setting' whereby interests and awareness about possible standards is attempted to be aligned and raised, which has been reported to increase the chances for successful standardization [21]. Other stakeholders that may have an influence on the standardization process include 'suppliers' who deliver complementary goods.

Market mechanisms, such as network effects, are relevant factors for market success of standards. These effects refer to the situation that a product, in which a standard is implemented, increases in value the more it is adopted, as more connections can be made between users that adopt the product [33]. This can create a bandwagon effect where users will follow each other in their choice for a standard. In addition, the number of alternative standards that exist next to each other in the market will affect market uncertainty.

The factors discussed above all apply to single-mode standardization. Despite the rich literature on single-mode standardization processes and the relevant factors for each of the three modes of standardization, little is known about the factors that are relevant in case of multi-mode standardization.

\section{Method}

In order to explore which factors affect the selection of standards in a situation of multi-mode standardization, the case of phosphorus recovery from municipal waste water, as discussed in the introduction, was chosen as a sample case of multi-mode standardization. The reason is that both 
individual firms, standards organizations, and regulatory agencies are involved in the standardization of this phosphorus recovery from waste water. Furthermore, Freimuth et al. [34] suggest that waste water treatment in Germany shows forms of multi-mode standardization.

Empirical data was gathered in two rounds of interviews. In the first round, the relevant factors were determined. In the second round, relative importance was assigned to those factors using the best worst method (BWM) [35,36].

\subsection{Best Worst Method}

The best worst method (BWM) has been applied successfully in past research to evaluate the importance of factors for standard dominance for various cases (see, e.g., reference [37]). The BWM consists of 5 steps. First, a list consisting of all decision criteria $\left(c_{1}, c_{2}, \ldots, c_{n}\right)$ must be established. In the second step, experts will determine which criterion is the best criterion and which criterion is the worst criterion. In a third step, the experts compare the best criterion with the other criteria. They use numbers from 1 (equally important) to 9 (extremely more unimportant) to assign their preferences. This results in the best-to-others vector: $A_{B}=\left(a_{B 1}, a_{B 2}, \ldots, a_{B n}\right)$. In the fourth step, in a similar way as in the third step, experts compare the worst criterion with the other criteria resulting in the worst-to-others vector: $A_{w}=\left(a_{1 w}, a_{2 w}, \ldots, a_{n w}\right)^{T}$. This step measures the level of consistency in the answers given by the experts. The fifth step consists of the calculation of the optimal weights using the following model:

$$
\min \max _{j}\left\{\left|w_{B}-a_{B j} w_{j}\right|,\left|w_{j}-a_{j W} W_{w}\right|\right\}
$$

s.t.

$$
\begin{gathered}
\sum_{j} w_{j}=1, \\
w_{j} \geq 0, \text { for all } j,
\end{gathered}
$$

which is equal to the following linear programming model

$$
\min \xi^{L}
$$

s.t.

$$
\begin{gathered}
\left|\frac{w_{B}}{w_{j}}-a_{B j}\right| \leq \xi^{L}, \text { for all } j, \\
\left|\frac{w_{j}}{w_{W}}-a_{j W}\right| \leq \xi^{L}, \text { for all } j, \\
\sum_{j} w_{j}=1, \\
w_{j} \geq 0, \text { for all } j .
\end{gathered}
$$

$\xi^{\mathrm{L}}$ is the consistency ratio. Scores are considered consistent if the consistency ratio $\xi^{\mathrm{L}}$ is not much higher than 0 .

\subsection{First Round of Interviews: Determining Relevant Factors}

For step 1 of the BWM, a sample of all the experts who are involved in managing the struvite installation at their location were interviewed (see Table 1 for details of the interviewees). Three semi-structured interviews were conducted, recorded, and transcribed. The questions that were asked to the three interviewees were the same and are available upon request. Subsequently, the interviewees were asked to evaluate various factors for the selection of standards for multi-mode standardization as reported in [11,14-28]. If a factor was mentioned to be relevant by an expert, the factor was seen as a relevant factor. The possibility was left open to come up with new factors that were not included in the literature. 
Table 1. Background of interviewees.

\begin{tabular}{ccc}
\hline Interviewee & Type of Struvite Installation & Organization \\
\hline 1 & NuReSys and Pearl Ostara & Waterschap Vallei en Veluwe \\
2 & Airprex & Waterschap Amstel Gooi en Vecht \\
3 & Phospaq & Waterschap Tilburg-Noord \\
\hline
\end{tabular}

\subsection{Second Round of Interviews}

For steps $2-5$ of the BWM, the same experts who were interviewed to identify the relevant factors, complemented with four additional experts were interviewed to identify the weights. These four additional experts are all involved in managing a struvite installation. Hence, in total, seven persons were interviewed: two from Waterschap Vallei and Veluwe, two from Waterschap Amstel Gooi and Vecht, two from Waterschap Aa and Maas, and one from Waterschap Tilburg-Noord.

\section{Results}

According to the experts, relevant factors for standard selection in a multi-mode standardization context for the case of phosphorus recovery from municipal waste water include the following (a reference to the interviewee(s) who mentioned this factor is included in parentheses behind each factor): 'financial strength' (I1, I3), 'technological superiority' (I1, I2, I3), 'compatibility' (I1, I2, I3), 'complementary goods' (I1, I2), 'pricing strategy' (I2, I3), 'appropriability strategy' (I1), 'marketing communications' (I1, I2), 'financial support' (I1), 'agenda setting' (I3), 'current installed base' (I2, I3), and 'suppliers' (I1, I3). See Section 2 for a more detailed description of these factors.

Eleven factors were found to be relevant, which exceeds the number of factors that can be remembered by individuals [38]. Therefore, a categorization had to be applied. During the interviews in the first round, some experts indicated that some relevant factors were not directly affected by technology provider of the struvite installation, for example, financial support provided by the government. Therefore, it was chosen to categorize the factors into primary and secondary factors. The primary factors can be influenced by the technology provider, while the secondary factors are influenced by other actors. For example, technological superiority has been categorized as a primary factor as it is affected by the technology provider. However, the price that is being paid for a struvite installation is not determined by the technology provider and was therefore categorized as a secondary factor. The factors 'compatibility', 'appropriability strategy', 'marketing communications', and 'current installed base' were categorized as primary factors. 'financial strength', 'complementary goods', 'financial support', 'agenda setting', and 'suppliers' were classified as secondary factors.

The results of the BWM and the calculated consistency ratios are shown in Tables 2 and 3, respectively. All consistency ratios $\left(\xi^{\mathrm{L}}\right)$ lie close enough to 0 (see Table 2), meaning that the results are sufficiently consistent.

Table 2. Consistency ratios.

\begin{tabular}{rcccccccc}
\hline & Expert 1 & Expert 2 & Expert 3 & Expert 4 & Expert 5 & Expert 6 & Expert 7 & Average \\
\hline $\begin{array}{r}\text { Primary factors } \\
\text { Secondary }\end{array}$ & 0.14 & 0.07 & 0.15 & 0.16 & 0.09 & 0.07 & 0.13 & 0.12 \\
factors & & 0.10 & 0.08 & 0.13 & 0.09 & 0.12 & 0.12 & 0.10 \\
\hline
\end{tabular}


Table 3. Local and global average weights.

\begin{tabular}{llllllllcc}
\hline Factors & Expert 1 & Expert 2 & Expert 3 & Expert 4 & Expert 5 & Expert 6 & Expert 7 & Local Average Weight & Global Average Weight \\
\hline Primary factors & 0.89 & 0.83 & 0.67 & 0.67 & 0.67 & 0.33 & 0.67 & \\
Technological superiority & 0.17 & 0.37 & 0.31 & 0.47 & 0.47 & 0.42 & 0.39 & 0.37 \\
Compatibility & 0.37 & 0.22 & 0.48 & 0.21 & 0.28 & 0.25 & 0.26 & 0.30 \\
Current installed base & 0.25 & 0.22 & 0.09 & 0.16 & 0.11 & 0.12 & 0.13 & 0.16 \\
Appropriability strategy & 0.17 & 0.15 & 0.08 & 0.13 & 0.08 & 0.16 & 0.17 & 0.13 \\
Market communications & 0.04 & 0.04 & 0.04 & 0.05 & 0.05 & 0.05 & 0.04 & 0.04 \\
Secondary factors & 0.11 & 0.17 & 0.33 & 0.33 & 0.33 & 0.67 & 0.33 & 0.24 \\
Agenda setting & 0.43 & 0.29 & 0.22 & 0.19 & 0.15 & 0.43 & 0.16 & 0.27 \\
Pricing strategy & 0.17 & 0.32 & 0.22 & 0.45 & 0.23 & 0.11 & 0.35 & 0.27 \\
Financial strength & 0.09 & 0.09 & 0.36 & 0.04 & 0.37 & 0.04 & 0.10 & 0.15 \\
Complementary goods & 0.04 & 0.21 & 0.11 & 0.12 & 0.11 & 0.19 & 0.24 & 0.15 \\
Financial support & 0.09 & 0.03 & 0.06 & 0.12 & 0.09 & 0.09 & 0.04 & 0.07 \\
Suppliers & 0.17 & 0.05 & 0.03 & 0.08 & 0.05 & 0.14 & 0.12 & 0.09 \\
\hline
\end{tabular}


Table 3 shows the highest scores for 'technological superiority' (0.24) and 'compatibility' (0.20), which means that they are considered to be the most important factors by the experts. The factors 'current installed base' (0.11), 'appropriability strategy' (0.09), 'agenda setting' (0.09), and 'pricing strategy' $(0.08)$ were considered as medium important factors by the experts. The factors 'financial strength (0.05), 'complementary goods' (0.05), 'market communications' (0.03), 'financial support' (0.03), and 'suppliers' (0.03) were considered as least important by the experts.

From the results, it appears that experts find two factors to be most important: technological superiority and compatibility. In other studies, technological superiority is also often seen as the most important factor by experts. It was a top ranking factor in various studies (see, e.g., reference [37]). This provides further support that, according to the experts, guaranteeing 'technological superiority' is very important in the standardization process.

Compatibility was seen as a very important factor because experts argued that the struvite installations must properly fit in the (water flow) process that goes on in the treatment plants. The functioning of the primary process of the treatment plant should not be dependent on the functioning of the struvite installation and the treatment plant should still work if the struvite installation is switched off. Although in recent literature [37], 'compatibility' is considered a relevant factor for standardization, it did not emerge as one of the most important factors before. A possible explanation may be that, in the other articles, the technologies are considered essential, whereas struvite installation is seen as an additional technology within the treatment plants, making compatibility with the 'basic technology' more important.

\section{Conclusions}

In this paper, factors that affect multi-mode standardization in the context of phosphorous recovery from municipal waste water were analyzed. Both technological superiority and compatibility were seen by experts as relevant and important factors. The research contributes to standardization research in different ways. First, this is the first study that studies factors for standard selection for multi-mode standardization processes. In addition, it is the first time that the BWM has been used in the case of phosphorus recovery from waste water. While most factors found have been reported in the literature on market-based standardization, two factors are new: 'agenda setting' and 'financial support'. Further research is needed to see to what extent these factors are related to the 'RRI-character' of the technology. Especially the factor 'agenda setting' may be linked to the technology's RRI character (going beyond mere efficiency and trying to address multiple goals at the same time) and the wish to create more room for such technologies.

Beyond this specific application domain, this is one of the first studies that empirically looks at multi-mode standardization, a phenomenon that has only recently been proposed in the literature. More cases of multi-mode standardization are needed to validate the factors identified in the current study and to identify possible other factors that have not emerged yet. Although standardization always has a very context-specific component, a richer database of standardization cases may allow us to draw more general conclusions and possibly also identify necessary conditions for multi-mode standard selection. Based on the study reported here and the current literature, it is too early to make any firm statement about the possibility to derive an integrated framework that is applicable to specific sectors or even all standardization arenas, let alone to develop such a framework.

The most important practical contribution is the possible use of the results for selecting a struvite installation to be used in a waste water treatment plant. A treatment plant that has to make a decision concerning which type of struvite installation to use should pay special attention to technological superiority and compatibility of the solutions that are offered. In terms of RRI, the paper suggests that for technologies that have societal aspirations, more factors, or slightly different factors may be relevant for successful standardization. This may be especially relevant if RRI technologies are to be implemented on a large scale. 
Author Contributions: The article's concept and main message were developed in joint discussions. G.v.d.K. wrote the final paper. L.v.d.E. did the data collection and analysis. G.v.d.K., L.v.d.E., and N.D. revised various versions of the manuscript. All authors have read and agreed to the published version of the manuscript.

Funding: This research received no external funding.

Conflicts of Interest: The authors declare no conflict of interest.

\section{References}

1. Buunen, A.; Clevering-Loeffen, P.; van Leusden, M.; van Opijnen, J.; Wiegant, W. Handboek Stikstofen Fosforverwijdering uit Communaal Afvalwater op RWZI's; Stichting Toegepast Onderzoek Waterbeheer: Amersfoort, The Netherlands, 2017.

2. Korving, L. Fosfaat, Van Verwijdering Naar Terugwinning; NEMO Kennislink: Amsterdam, The Amsterdam, 2018.

3. Desmidt, E.; Ghyselbrecht, K.; Zhang, Y.; Pinoy, L.; Van der Bruggen, B.; Verstraete, W.; Meesschaert, B. Global phosphorus scarcity and full-scale P-recovery techniques: A review. Crit. Rev. Environ. Sci. Technol. 2015, 45, 336-384. [CrossRef]

4. StatLine. Zuivering van Stedelijk Afvalwater, Technische Kenmerken Installaties; CBS: The Hague, The Netherlands, 2016.

5. Van Gelder, P.; Doorn, N.; De Gijt, J. Responsible innovation in the hydraulic engineering sector. In Responsible Innovation; Ortt, R., Kamp, L., Van de Poel, I., Van Putten, D., Eds.; Routledge: New York, NY, USA, 2020.

6. de Vries, H.; Jakobs, K.; Egyedi, T.M.; Eto, M.; Fertig, S. Standardization: Towards an Agenda for Research. Int. J. Stand. Res. 2018, 16, 52-59. [CrossRef]

7. Wiegmann, P.M.; de Vries, H.J.; Blind, K. Multi-mode standardisation: A critical review and a research agenda. Res. Policy 2017, 46, 1370-1386. [CrossRef]

8. Cusumano, M.A.; Mylonadis, Y.; Rosenbloom, R.S. Strategic maneuvering and mass-market dynamics: The triumph of VHS over Beta. Bus. Hist. Rev. 1992, 66, 51-94. [CrossRef]

9. Gallagher, S.R. The battle of the blue laser DVDs: The significance of corporate strategy in standards battles. Technovation 2012, 32, 90-98. [CrossRef]

10. Van de Kaa, G.; De Vries, H. Factors for winning format battles: A comparative case study. Technol. Forecast. Soc. Chang. 2015, 91, 222-235. [CrossRef]

11. Van de Kaa, G.; De Bruijn, J.A. Platforms and incentives for consensus building on complex ICT systems: The development of WiFi. Telecommun. Policy 2015, 39, 580-589. [CrossRef]

12. Bakker, S.; Leguijt, P.; Van Lente, H. Niche accumulation and standardization-The case of electric vehicle recharging plugs. J. Clean. Prod. 2015, 94, 155-164. [CrossRef]

13. Starkl, M.; Brunner, N.; Werner Helmut Hauser, A.; Feil, M.; Kasan, H. Addressing Sustainability of Sanitation Systems:Can it be Standardized? Int. J. Stand. Res. 2018, 16, 39-51.

14. Axelrod, R.; Mitchell, W.; Thomas, R.E.; Bennett, D.S.; Bruderer, E. Coalition Formation in Standard-Setting Alliances. Manag. Sci. 1995, 41, 1493-1508. [CrossRef]

15. Blind, K.; Mangelsdorf, A. Motives to standardize: Empirical evidence from Germany. Technovation 2016, 48-49, 13-24. [CrossRef]

16. Dan, S.M. How interface formats gain market acceptance: The role of developers and format characteristics in the development of de facto standards. Technovation 2019, 88, 102054. [CrossRef]

17. de Vries, H.J.; Verhagen, W.P. Impact of changes in regulatory performance standards on innovation: A case of energy performance standards for newly-built houses. Technovation 2016, 48, 56-68. [CrossRef]

18. Farrell, J.; Saloner, G. Coordination through committees and markets. RAND J. Econ. 1988, 19, $235-252$. [CrossRef]

19. Funk, J.L.; Methe, D.T. Market- and committee-based mechanisms in the creation and diffusion of global industry standards: The case of mobile communication. Res. Policy 2001, 30, 589-610. [CrossRef]

20. Gao, X. A latecomer's strategy to promote a technology standard: The case of Datang and TD-SCDMA. Res. Policy 2014, 43, 597-607. [CrossRef]

21. Garud, R.; Jain, S.; Kumaraswamy, A. Institutional entrepreneurship in the sponsorship of common technological standards: The case of Sun Microsystems and Java. Acad. Manag. J. 2002, 45, 196-214. 
22. Leiponen, A.E. Competing through cooperation: The organization of standard setting in wireless telecommunications. Manag. Sci. 2008, 54, 1904-1919. [CrossRef]

23. Markus, M.L. Industry-Wide Information Systems Standardization as Collective Action: The Case of the U.S. Residential Mortgage Industry. MIS Q. 2006, 30, 439-465. [CrossRef]

24. Ranganathan, R.; Ghosh, A.; Rosenkopf, L. Competition-Cooperation interplay during multifirm technology coordination: The effect of firm heterogeneity on conflict and consensus in a technology standards organization. Strateg. Manag. J. 2018, 39, 3193-3221. [CrossRef]

25. Spulber, D.F. Standard setting organisations and standard essential patents: Voting and markets. Econ. J. 2016, 129, 1477-1509. [CrossRef]

26. Van de Kaa, G.; Greeven, M.; van Puijenbroek, G. Standards battles in China: Opening up the black-box of the Chinese government. Technol. Anal. Strateg. Manag. 2013, 25, 567-581. [CrossRef]

27. Van de Kaa, G.; Van den Ende, J.; De Vries, H.J.; Van Heck, E. Factors for winning interface format battles: A review and synthesis of the literature. Technol. Forecast. Soc. Chang. 2011, 78, 1397-1411. [CrossRef]

28. Van Wegberg, M. Standardization process of systems technologies: Creating a balance between competition and cooperation. Technol. Anal. Strateg. Manag. 2004, 16, 457-478. [CrossRef]

29. Shapiro, C.; Varian, H.R. The art of standards wars. Calif. Manag. Rev. 1999, 41, 8-32. [CrossRef]

30. Egyedi, T.M.; Spirco, J. Standards in transitions: Catalyzing infrastructure change. Futures 2011, 43, 947-960. [CrossRef]

31. Bakker, S.; van Lente, H.; Meeus, M. Dominance in the prototyping phase-The case of hydrogen passenger cars. Res. Policy 2012, 41, 871-883. [CrossRef]

32. Garud, R.; Kumaraswamy, A. Changing Competitive Dynamics in Network Industries: An Exploration of Sun Microsystem' Open Systems Strategy. Strateg. Manag. J. 1993, 14, 351-369. [CrossRef]

33. Katz, M.L.; Shapiro, C. Network externalities, competition, and compatibility. Am. Econ. Rev. 1985, 75, 424-440.

34. Freimuth, C.; Oelmann, M.; Amann, E. Development and prospects of standardization in the German municipal wastewater sector. Sci. Total Environ. 2018, 635, 375-389. [CrossRef]

35. Rezaei, J. Best-worst multi-criteria decision-making method. Omega Int. J. Manag. S. 2015, 53, 49-57. [CrossRef]

36. Rezaei, J. Best-worst multi-criteria decision-making method: Some properties and a linear model. Omega Int. J. Manag. S. 2016, 64, 126-130. [CrossRef]

37. Van de Kaa, G.; Kamp, L.M.; Rezaei, J. Selection of biomass thermochemical conversion technology in the Netherlands: A best worst method approach. J. Clean. Prod. 2017, 166, 32-39. [CrossRef]

38. Miller, G.A. The magical number seven plus or minus two: Some limitations on our capacity for processing information. Psychol. Rev. 1956, 63, 81-97. [CrossRef] [PubMed] 